\title{
Osteoarthritis of the hip: the patient behind the disease
}

\author{
L. SOLOMON, C. M. SCHNITZLER, AND J.P. BROWETT
}

From the Department of Orthopaedic Surgery, University of the Witwatersrand, Johannesburg, South Africa

SUMMARY Previous epidemiological studies suggested that patients with osteoarthritis (OA) of the hip might constitute a definable subset of the population with characteristics that predispose them to joint failure. To investigate this possibility a comparative study of somatotype, bone density, disc degeneration, polyarticular joint degeneration, and soft-tissue calcification was carried out in 3 groups of individuals: (1) patients presenting with OA of the hip; (2) patients with acute femoral neck fracture; (3) healthy controls. OA of the hip was rare in patients with femoral neck fracture; conversely, patients with coxarthrosis did not have the low values for bone density seen in the fracture group. There were significant differences in somatotype in the 2 patient groups; 94\% of those with OA were endomorphic mesomorphs. Polyarticular OA occurred with the same prevalence in the 2 groups of women, but among males there was a significantly greater involvement of knees and hands in the OA group than in the fracture group. The highest incidence of joint calcification was found in the fracture group and the lowest in the OA group. It was concluded that patients with OA of the hip form a definable subset of the general population. Within this group the appearances of hip $\mathrm{OA}$ are determined by 3 interacting factors: mechanical stress, cartilage degeneration, and bone response.

Osteoarthritis (OA) of the hip was until fairly recent times thought of as a randomly occurring — and probably universal-degenerative disorder of the joint associated with ageing. More critical observation, however, has led to a reappraisal of this view. Epidemiological studies have shown that $O A$ in general is more common in women than in men. ${ }^{1} \mathrm{OA}$ of the hip is much more common in Caucasian peoples than in the Southern Chinese ${ }^{2}$ or South African Negroes. ${ }^{3}$ Even within a population group where $\mathrm{OA}$ of the hip is common (e.g., Caucasian females), the prevalence differs significantly in specific subsets. Thus patients with fracture of the femoral neck, despite their advanced age, seldom have any sign of hip OA.

These findings prompted the hypothesis that patients with $O A$ of the hip constitute a definable subset of the normal population, with physical characteristics that predispose to 'joint failure.'

This paper presents a comparative study of somatotype, bone status, disc degeneration, poly-

Accepted for publication 3 March 1981

Correspondence to Professor L. Solomon, Department of Orthopaedic Surgery, Medical School, University of the Witwatersrand, Johannesburg 2001, South Africa. articular disease, and soft-tissue calcification in 3 groups of individuals: (1) patients presenting to the Johannesburg Hospital with advanced OA of the hip; (2) patients in the same hospital with acute fracture of the femoral neck, who had a negligible prevalence of coxarthrosis; (3) healthy controls from a random population survey carried out in Johannesburg.

\section{Materials and methods}

ASSESSMENT OF OA, PERIARTICULAR

CALCIFICATION, AND DISC DEGENERATION

The study involved 105 patients- -57 women and 48 men-with advanced OA of the hip (the OA group), 100 patients -85 women and 15 men-with acute fracture of the femoral neck (the fracture group), and 176 'normal' individuals-111 women and 65 men-assessed clinically and radiographically in a random population survey in a working class suburb of Johannesburg. All subjects were Caucasians between the ages of 55 and 80 years.

Clinical examination of the joints provided a record of tenderness, swelling, deformity, and limitation of movement.

Radiographs of both hips, both knees, and the 
hands were obtained in each case. Osteoarthritis was graded according to the Rome Criteria. ${ }^{4}$ Its prevalence in each joint (or joint group in the case of the hands) was expressed as a percentage of the total number of such joints assessed (e.g., 10 affected knees in 100 patients gives a prevalence of $5 \%$ of the 200 knees). Radiographic evidence of calcification in articular cartilage and in periarticular tissues was noted for each joint.

Disability of the lumber spine was assessed clinically in terms of pain and limitation of movement and graded as a spinal score from $0-6$. Disc degeneration was assessed by a single observer from posteroanterior and lateral radiographs of the lumber spine. Severity and extent of involvement were graded on a subjective scale of $0-3+$.

\section{SOMATOTYPING}

Detailed somatotyping was carried out only in the $\mathrm{OA}$ and fracture groups. Since OA of the hip and fracture of the neck of the femur are thought to be mutually exclusive disorders, ${ }^{5}$ any discriminating features of somatotype could be expected to show up in a comparison of the 2 groups.

Height, weight, girth, bisacromial width, pelvic width, biceps girth, calf girth, and skinfold thickness were measured. Somatotype was plotted by the Heath-Carter modification of Sheldon's method ${ }^{6}$ on a 2-dimensional triangular-shaped somatochart with 3 axes indicating mesomorphy, ectomorphy, and endomorphy. Discriminant analysis was used to assess which of the above parameters permitted significant separation of the 2 patient groups.

\section{BONE DENSITY}

Radiogrammetric assessment of 'bone density' was carried out on standard radiographs of the hands. The overall width (D) and medullary width (d) were measured at the midpoint of the second metacarpal of each hand. On the assumption that the bone was cylindrical at its waist, bone mass was expressed as the cross-sectional cortical area: $\frac{\pi}{4}\left(D^{2}-d^{2}\right)$, but omitting $\frac{\pi}{4}$ by convention. Bone density was then expressed as the ratio of cortical area to total crosssectional area, which was given by the formula

$$
\frac{D^{2}-d^{2}}{D^{2}}
$$

(Nordin $e t$ al. ${ }^{7}$ ). Taking the average for the 2 hands in each case, we obtained mean values for quinquennial age groups.

'Bone turnover' was measured by quantitative microradiography and quantitative histomorphometry carried out on iliac crest biopsy specimens obtained from 19 patients with OA of the hip and 19 with fracture of the femoral neck.

\section{Results}

\section{OA OF THE HIP}

The prevalence of radiographic OA of the hip in the normal population is shown in Table 1 . OA of all grades was more than twice as common in men as in women. Severe OA (grades 3 and 4 ) occurred in $6.2 \%$ of men and only $0.9 \%$ of women in the random survey.

The prevalence of OA in the hip joints of patients in the OA and fracture groups is shown in Table 2. The figures confirm the general observation that $\mathrm{OA}$ of the hip (and certainly severe OA) is very uncommon in men and women with femoral neck fractures.

\section{SOMATOTYPE}

Patients with OA of the hip were on average somewhat shorter and heavier than the mean for the normal population, but these differences were not statistically significant.

Detailed somatotyping for the 2 patient groups is shown in Figs. 1 and 2. There were significant differences between the 2 groups: all but $4 \%$ of those with OA were endomorphic mesomorphs, while $25 \%$ of those with femoral neck fracture had features of ectomorphy.

Discriminant analysis within each sex group was carried out to determine which factors allow significant differentiation of the 2 patient groups. The results are shown in Table 3. The only variables which contributed to a statistically significant degree towards discrimination between the $\mathrm{OA}$ and fracture groups were the biceps girth in females and the calf girth in males.

Table 1 Radiographic $O A$ of the hip in normal population

\begin{tabular}{|c|c|c|c|c|c|c|}
\hline \multirow{2}{*}{$\begin{array}{l}\text { Age } \\
\text { group }\end{array}$} & \multicolumn{3}{|c|}{ Males } & \multicolumn{3}{|c|}{ Females } \\
\hline & No. & $\begin{array}{l}O A \\
\text { Gr. 2-4 }\end{array}$ & $\begin{array}{l}\text { OA } \\
\text { Gr. } 3-4\end{array}$ & No. & $\begin{array}{l}\text { OA } \\
\text { Gr. } 2-4\end{array}$ & $\begin{array}{l}\text { OA } \\
\text { Gr. } 3-4\end{array}$ \\
\hline $55-59$ & 16 & 2 & 1 & 28 & 2 & \\
\hline $60-64$ & 15 & 4 & & 30 & 2 & \\
\hline $65-69$ & 14 & 1 & & 22 & 2 & 1 \\
\hline $70-74$ & 11 & 4 & 2 & 16 & 2 & \\
\hline $75+$ & 9 & 4 & 1 & 15 & 2 & \\
\hline Total & 65 & 15 & 4 & 111 & 10 & 1 \\
\hline$\%$ & 100 & $23 \cdot 1$ & $6 \cdot 2$ & 100 & 9.0 & 0.9 \\
\hline
\end{tabular}

Table 2 Radiographic $O A$ in all hip joints of patients in the 'OA group' and the 'fracture group'

\begin{tabular}{llllr}
\hline & \multicolumn{2}{l}{ OA group } & \multicolumn{2}{l}{ Fracture group } \\
\cline { 2 - 5 } & Males & Females & Males & Females \\
\hline Number of hips & 96 & 114 & 30 & 170 \\
OA gr. 2-4 & 77 & 93 & 4 & 13 \\
OA gr. 3-4 & 65 & 84 & 0 & 2 \\
0-1 & 19 & 21 & 26 & 157 \\
\hline
\end{tabular}




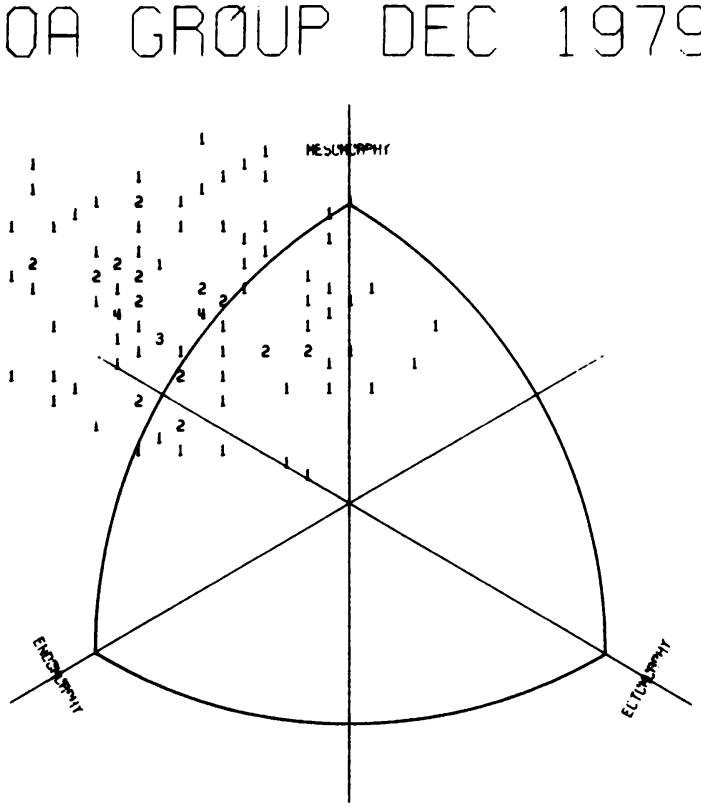

NUMBER OF SUBJECTS IS 104

Fig. 1 Somatotype distribution of patients with $O A$ of the hip.
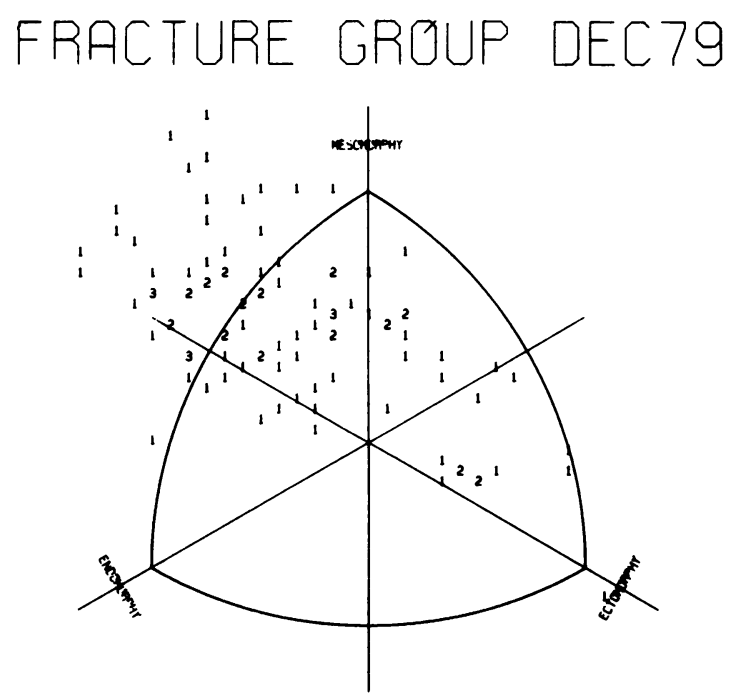

NUMBER OF SUBJECTS IS 100

Fig. 2 Somatotype distribution of patients with fracture of the femoral neck.
Table 3 Variables giving statistically significant discrimination between $O A$ and fracture groups

\begin{tabular}{lcl}
\hline Varlables & $\begin{array}{l}\text { Fvalues to enter } \\
\text { Females }\end{array}$ & Males \\
\hline Biceps girth & $41 \cdot 27$ & - \\
Age & $4 \cdot 37$ & - \\
Height & - & - \\
Calf girth & - & $37 \cdot 62$ \\
\% correctly classified & $73 \cdot 5$ & $85 \cdot 0$ \\
\hline
\end{tabular}

\section{BONE STATUS}

The normal age and sex specific patterns of bone density in a random Johannesburg population were used as standards. ${ }^{8}$ Mean values at 5-year intervals in the 2 patient groups are shown in Figs. 3 and 4. The fracture group, as might be expected, showed bone density values which were significantly less than the mean for the normal population. In the OA group, by contrast, bone density values were similar to those of the normal population for females and somewhat above the normal mean for males-especially in the age group above 70 years.

Quantitative microradiography of iliac crest biopsies showed marked differences between the 2 groups (Table 4). In the fracture groups only $1.7 \%$ of the bone surface was forming bone, whereas nearly twice as much was being resorbed. The imbalance must with time lead to bone loss. In the OA group on the other hand the discrepancy between bone formation and bone resorption was not nearly so marked. Bone formation occurred on $2.17 \%$ of the bone surface and resorption on $2.58 \%$. Though this would theoretically still lead to a net loss of bone, the rate would be much slower. These results are in keeping with the radiogrammetric assessment of metacarpal density described above.

Further evidence for good bone formation in OA was the appearance of large numbers of normal looking osteoblasts on bone forming surfaces, contrasting with sparsely distributed, small, flat cells in specimens from the fracture group.

\section{POLYARTICULAR OSTEOARTHRITIS}

The incidence of polyarticular joint involvement in the 2 groups of patients is shown in Figs. 5 (females) and 6 (males). Among the females, although there were significantly more complaints about pain in the

Table 4 Bone formation and bone resorption in $O A$ and femoral neck fracture

\begin{tabular}{lll}
\hline & OA group & Fracture group \\
\hline Number & 19 & 19 \\
Bone formation & $2 \cdot 17 \%$ & $1 \cdot 71 \%$ \\
Bone resorption & $2 \cdot 58 \%$ & $3 \cdot 23 \%$ \\
\hline
\end{tabular}


wrist and distal interphalangeal joints, the incidence and distribution of radiological OA did not differ significantly in the 2 patient groups. Among the males there was a significantly greater incidence of $O A$ in the finger joints and knees in the OA group than in the fracture group $(p<0 \cdot 01)$.

A particularly interesting finding emerged when all patients from both groups were pooled and then divided for comparison on the basis of severe (grade 3-4) or mild (grade 0-2) OA of the distal inter- phalangeal (DIP) joints. This was done in order to determine whether patients with polyarticular DIP arthritis had a greater than usual liability to develop OA of the hip. The results are shown in Table 5. As might be expected, those with severe DIP arthritis had a significantly higher incidence of proximal interphalangeal (PIP) and metacarpophalangeal (MCP) arthritis. The same was true of the knee but not of the hip, where severity of DIP arthritis did not appear to be correlated with coxarthrosis.

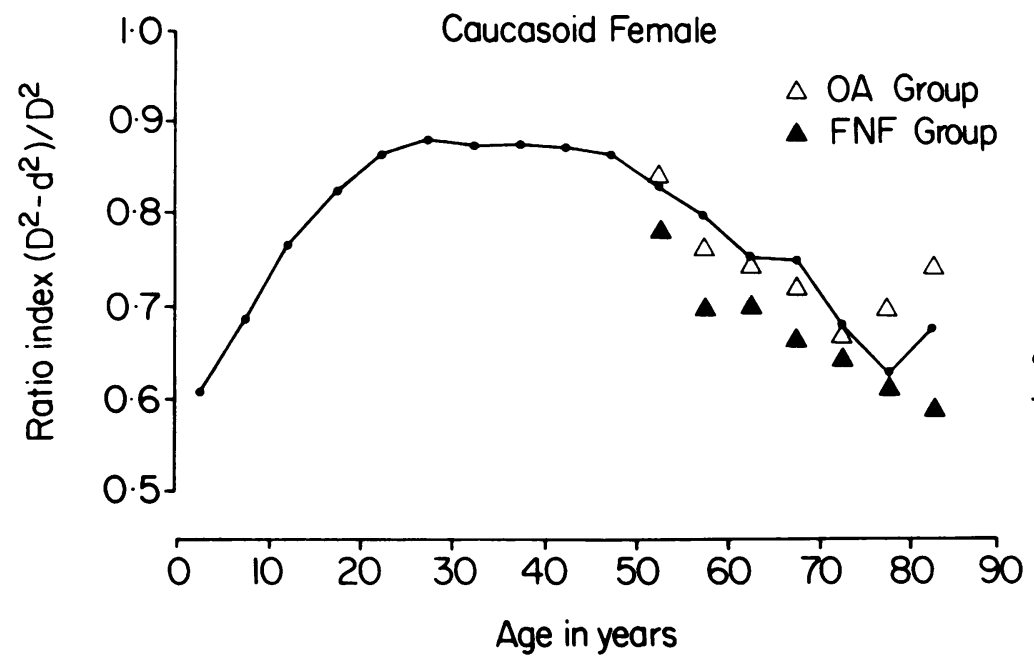

Fig. 3 Mean values for bone density in patients with $O A$ and femoral neck fractures (females).

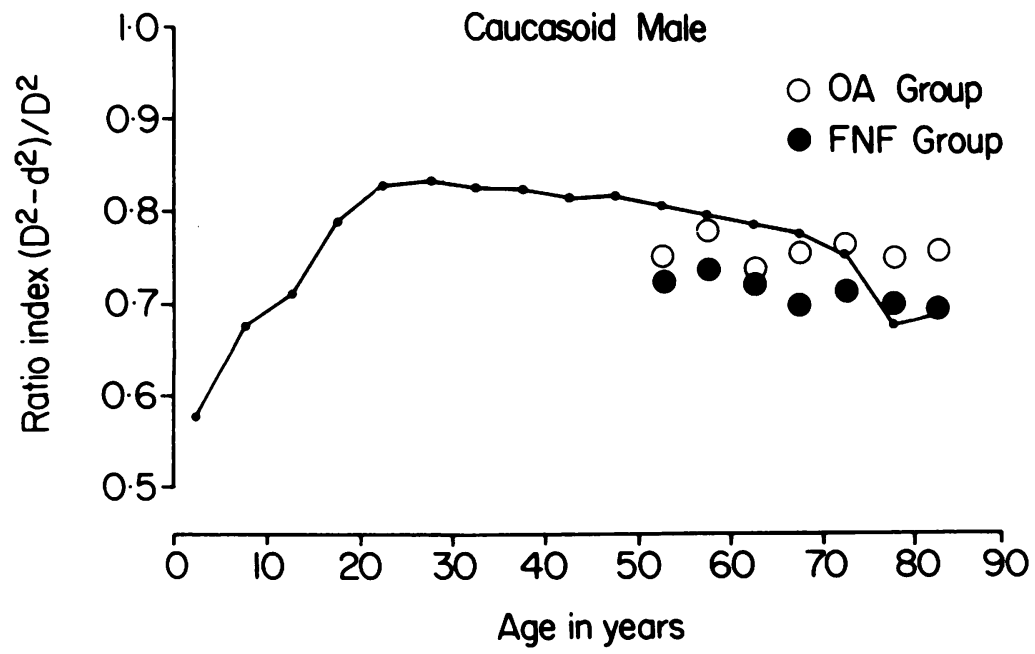

Fig. 4 Mean values for bone density in patients with $O A$ and femoral neck fractures (males). 
Table 5 OA of other joints in all subjects with DIP OA grades 3 and 4 compared with subjects with DIP OA grades 0-2

\begin{tabular}{|c|c|c|c|c|}
\hline & \multicolumn{2}{|c|}{ DIP OA grades $0-2$} & \multicolumn{2}{|c|}{$D I P O A$ grades 3 and 4} \\
\hline & Females & Males & Females & Males \\
\hline$n$ & $106(212 \mathrm{jts})$ & 54 (108 jts) & 36 (72 jts) & $9(18 \mathrm{jts})$ \\
\hline PIP & $35(16 \cdot 5 \%)$ & $11(10 \cdot 2 \%)$ & $46(63 \cdot 9 \%)$ & $13(72 \cdot 2 \%)$ \\
\hline $\mathrm{MCP}$ & $20(9.4 \%)$ & $9(8 \cdot 3 \%)$ & $30(41 \cdot 7 \%)$ & $5(27 \cdot 8 \%)$ \\
\hline CMC & $46(21 \cdot 7 \%)$ & $21(19 \cdot 4 \%)$ & $48(66 \cdot 7 \%)$ & $3(16 \cdot 7 \%)$ \\
\hline HIP & $85(40 \cdot 1 \%)$ & $66(61 \cdot 1 \%)$ & $26(36 \cdot 1 \%)$ & $13(72 \cdot 2 \%)$ \\
\hline
\end{tabular}

\section{FEMALES}

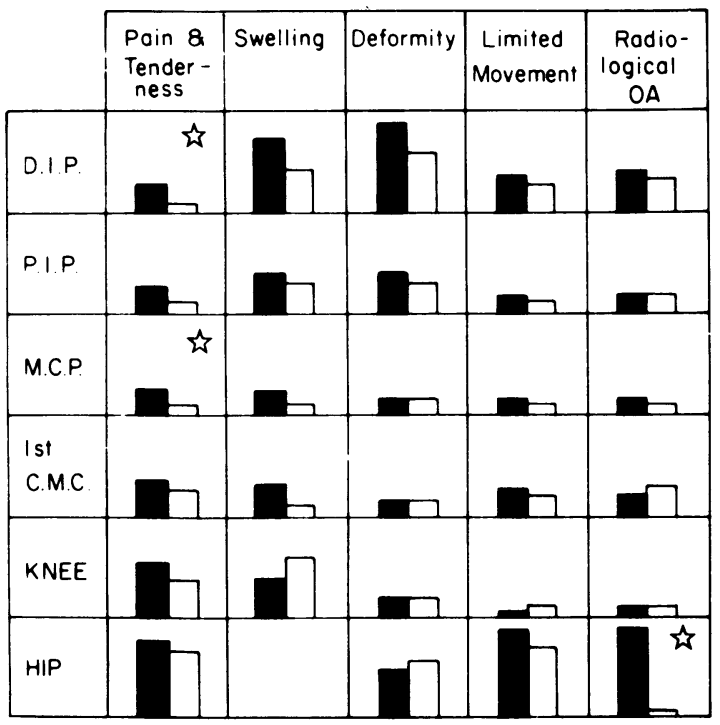

$\Leftrightarrow p<0.01$

Fig. 5 Percentage of female patients with clinical and radiological joint involvement (solid bars $=O A ;$ open bars $=$ fracture group).

J OINT CALCIFICATION

Neither frank chondrocalcinosis nor the lesser degrees of periarticular calcification were particularly common in patients with OA hip. On the contrary, the highest incidence of joint calcification $(19.2 \%$ of patients) occurred in the fracture group-i.e., those with the lowest incidence of hip OA (Table 6).

Table 6 Incidence of radiological articular calcification

\begin{tabular}{llcl}
\hline & Controls & OA hip & FNF \\
\hline$n$ & 58 & 80 & 73 \\
Calc. & 2 & 8 & 14 \\
$\%$ & $3 \cdot 4$ & $10 \cdot 0$ & $19 \cdot 2$ \\
\hline
\end{tabular}

p 0.05 .

$\mathrm{FNF}=$ femoral neck fracture.

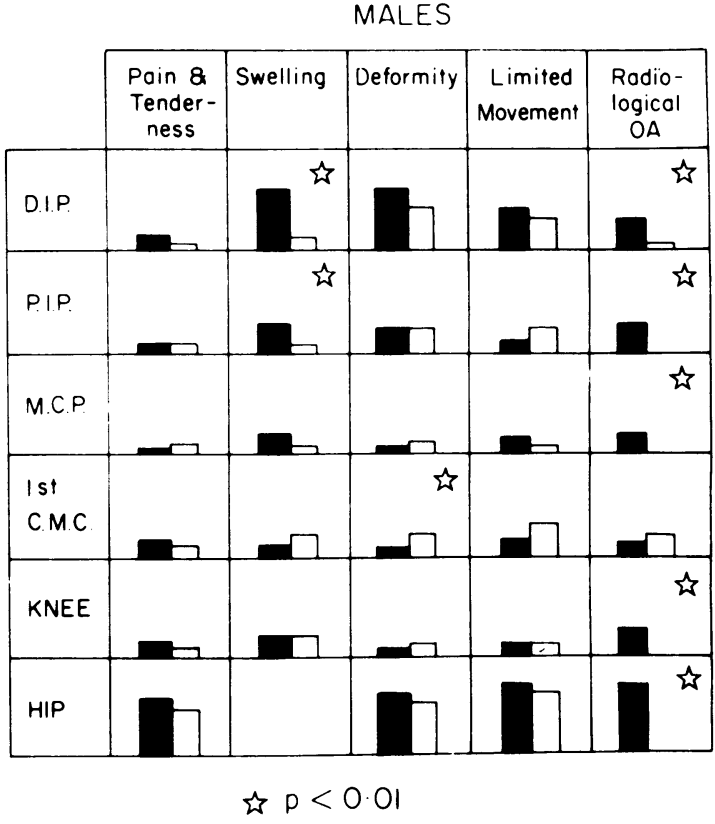

Fig. 6 Percentage of male patients with clinical and radiological joint involvement (solid bars $=O A$; open bars = fracture group).

\section{DISC DEGENERATION}

Accurate assessment of disc degeneration was difficult. The radiological appearances suggested a considerably greater involvement in the OA group than in the fracture group, but no statistical analysis was applied to these findings. A 'spinal score', based on clinical assessment of lumbar backache and limitation of movement, showed moderate-to-marked disability in $38 \%$ of patients with advanced OA hip and only $9 \%$ of those with femoral neck fracture.

\section{Discussion}

The study confirmed the notion that OA of the hip and femoral neck fracture are mutually exclusive. People with OA of the hip tend to have good muscle 
bulk and bone density. Previous studies have suggested that patients with OA of the hip actually have a significantly higher than normal bone mass. ${ }^{910}$ Our findings, however, showed that bone mass was equal to the normal mean between 50 and 70 years, but thereafter tended to remain at the same level during the postclimacteric period, which is usually associated with progressive osteoporosis.

The difference in bone density was accompanied by differences in body build. The finding that biceps girth in women and calf girth in men are significant discriminant factors in the 2 clinical groups may be related to differences in physical activity between the 2 groups. This finding warrants further exploration.

The near absence of OA hip in the fracture group can theoretically be explained by postulating that poor muscle bulk and diminished physical activity lessen joint loading, while osteoporotic bone is a good shock absorber which further protects the overlying cartilage against peak overload.

The present study did not confirm previous suggestions that OA hip is more common in women than in
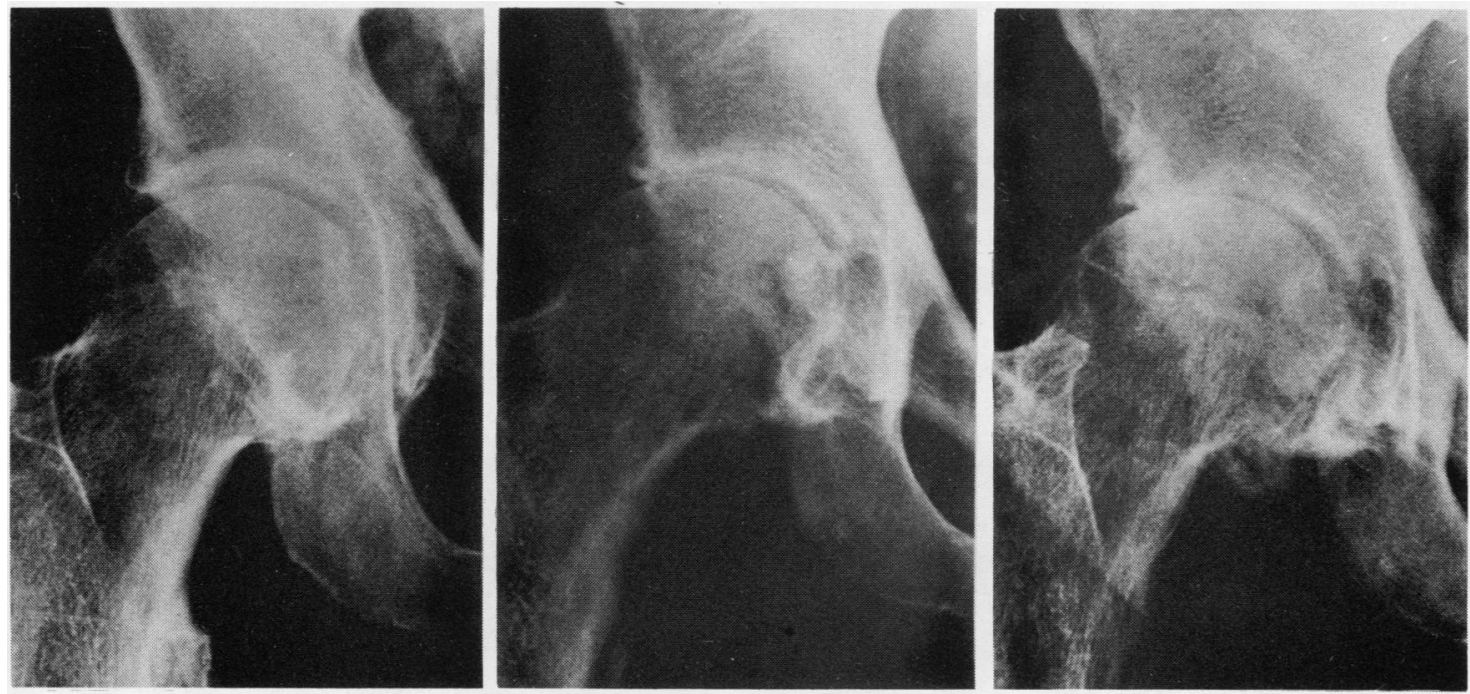

Fig. 7 Radiographs of the hip showing progressive development of 'hypertrophic OA' over 10 years.
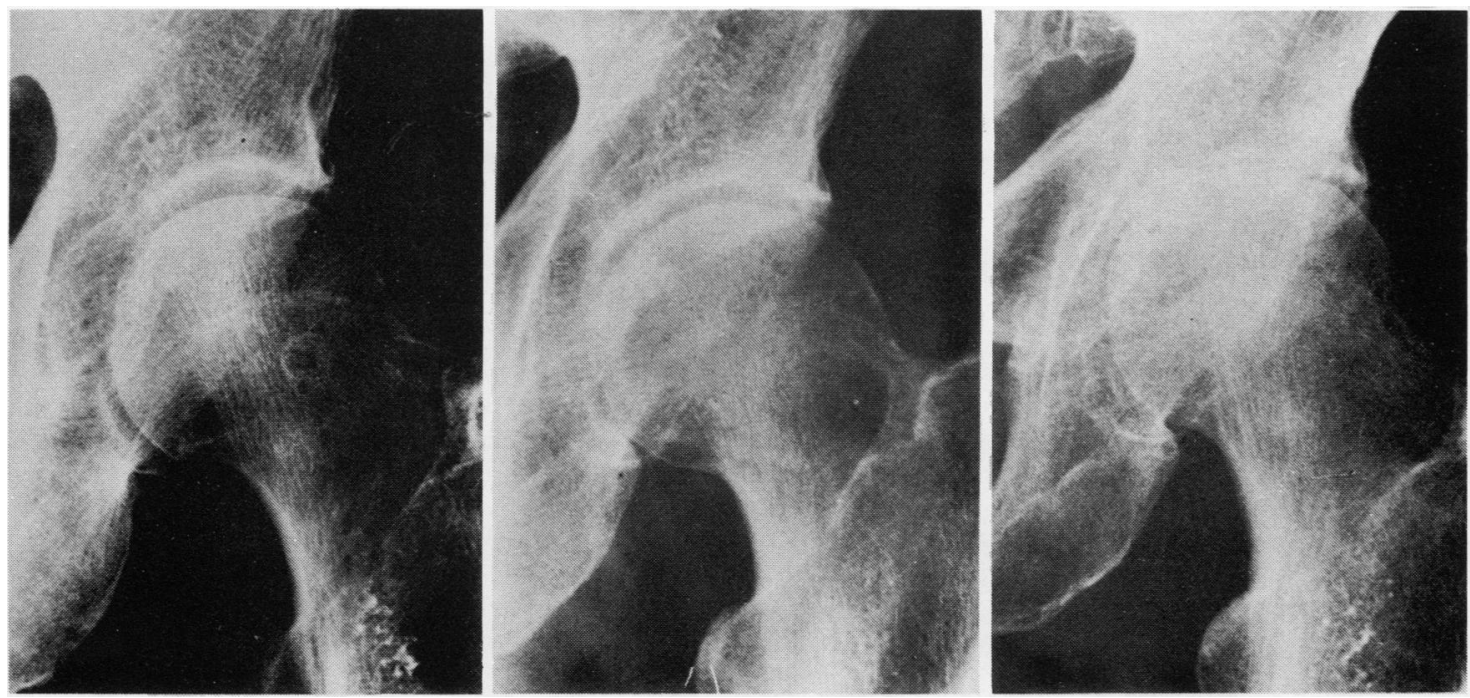

Fig. 8 Radiographs of the hip showing progressive development of 'atrophic OA' over 6 years. 

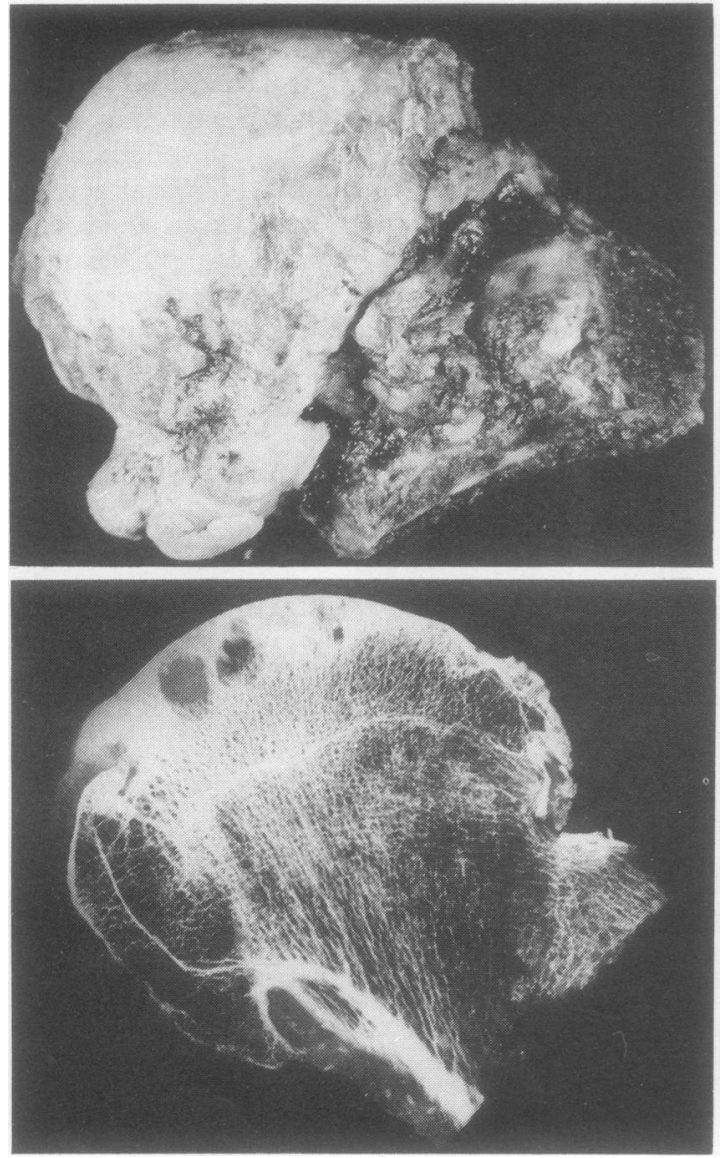

Fig. 9 Morbid anatomy (upper) and fine detail radiograph (lower) of femoral head with 'hypertrophic $O A$.

men. On the contrary, radiographic OA of all grades was more than twice as common in men as in women collected in a random population sample. Almost all of these subjects, however, were asymptomatic.

The idea that OA is due to an inflammatory disorder, and usually associated with polyarticular disease, has been explored repeatedly by rheumatologists $^{11-13}$ - with markedly conflicting results. Thus, while Roh et al. ${ }^{11}$ state that 'A significant higher degree of osteoarthrosis of the hand joints has been found in patients with primary osteoarthrosis of the hips compared with controls ...' Yazici et al. ${ }^{12}$ assert that 'Heberden's nodes are unrelated to osteoarthrosis of the knee or hip.'

In the present study we found no significant difference in polyarticular disease in females with $\mathrm{OA}$ and those with fractures. The men, however, did show a significant association between OA hip and polyarticular disease.

What became increasingly apparent during the
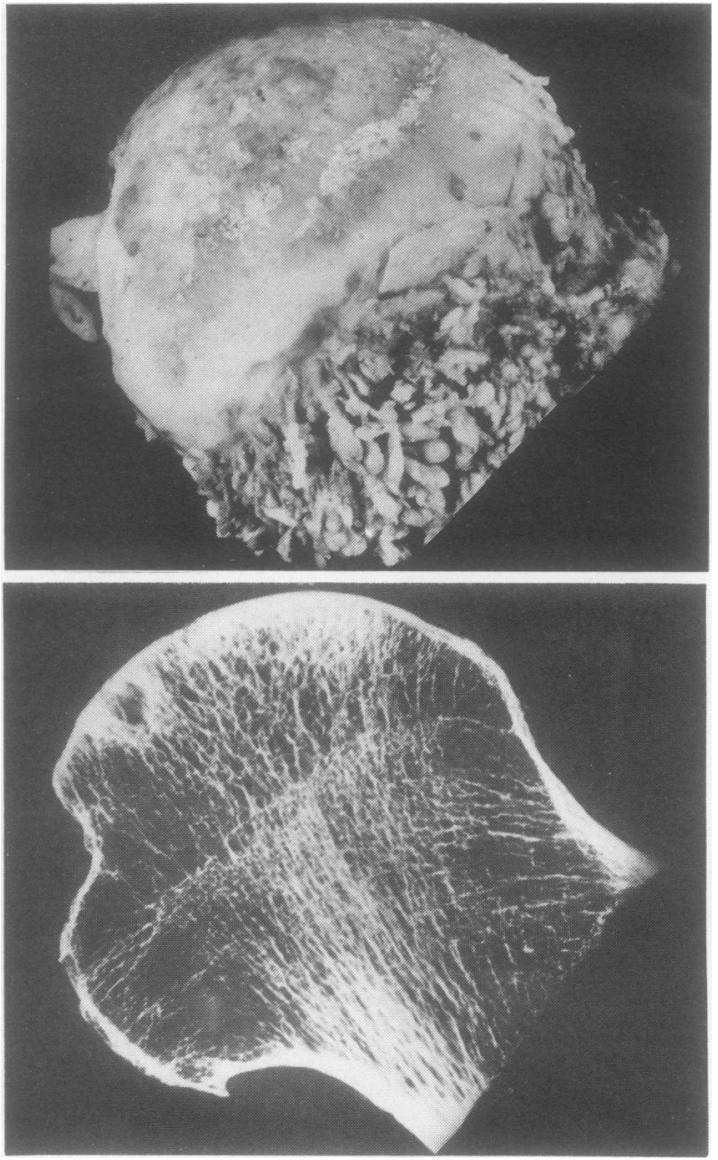

Fig. 10 Morbid anatomy (upper) and fine detail radiograph (lower) of femoral head with 'atrophic $O A$.'

study was that the term 'osteoarthritis' could with justification be applied to a range of disorders, some characterised by localised degeneration of a single large joint, some by concentric degeneration of one or both hips, some by polyarticular disease, and some by Heberden's nodes and DIP arthritis without involvement of any large joint. It is unhelpful to lump them together, though clearly the end stage in any single joint may be similar in all of them.

Polyarticular disease per se cannot be regarded as a pathogenetic marker for OA of the hip. Other surveys have shown that over $60 \%$ of women in the general population of 55 years and older have OA of the finger joints. ${ }^{14}$ One can therefore expect that over $60 \%$ of women with OA hip have 'polyarticular OA', whatever the cause of the hip disorder.

Our own studies have led us to the concept that OA of the hip occurs in at least 2 forms-a hypertrophic arthritis with localised loss of cartilage and florid new bone formation, and an atrophic arthritis with more 
widespread cartilage loss and little bone response (Figs. 7 and 8). The former group includes some patients who have undoubted mechanical or anatomical abnormalities of the joint; the latter includes a significant number with polyarticular disease and morbid anatomical features of an inflammatory disorder (Figs. 9 and 10).

Any hypothesis which seeks to explain the variable appearances of osteoarthritis must deal with 4 interacting factors: (1) mechanical overload; (2) inflammatory disease or cartilage degeneration; (3) good bone response; (4) poor bone response. A structural schema is presented in Fig. 11.

Extending this concept to a unitary hypothesis we suggest that the end-stage condition of any single joint which we call 'osteoarthritis' is the balance between articular destruction and repair (Fig. 12). If destruction is rapid (e.g., after septic arthritis, or in rheumatoid disease) and the repair phenomenon is poor the result will be an 'atrophic' arthritis. The same would be true of other nonspecific inflammatory disorders of joints which lead to rapid break-up of cartilage. If destruction is slow (e.g., due to minor anatomical or mechanical disorders causing localised overload), and especially if this begins at a young age when repair phenomena are still active in the remaining cartilage and bone, the result will be a 'hypertrophic' arthritis.

In the scheme described here 'osteoarthritis' disappears as a pathological entity and is reborn as a

HYPOTHESIS : PATTERNS OF OA

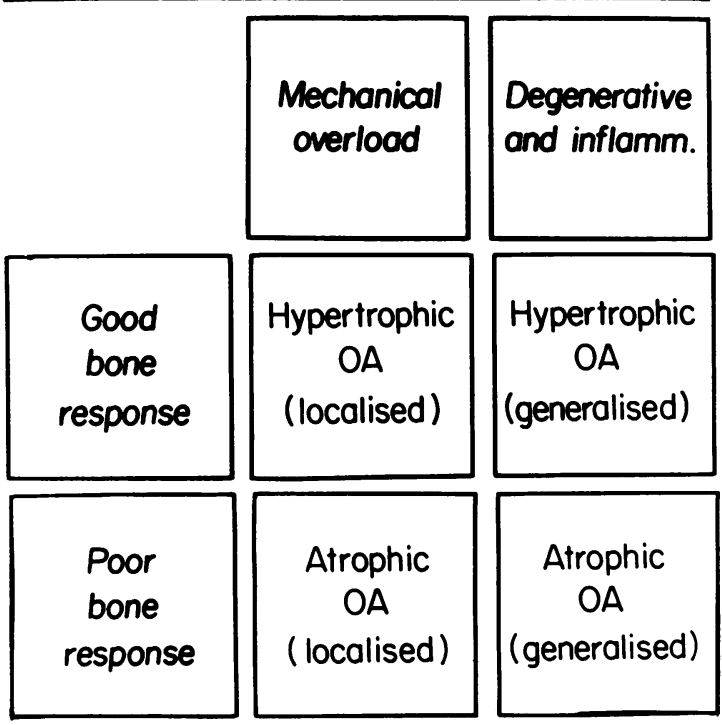

Fig. 11 Schema showing relationships of 4 factors in the development of different types of $O A$ of the hip.

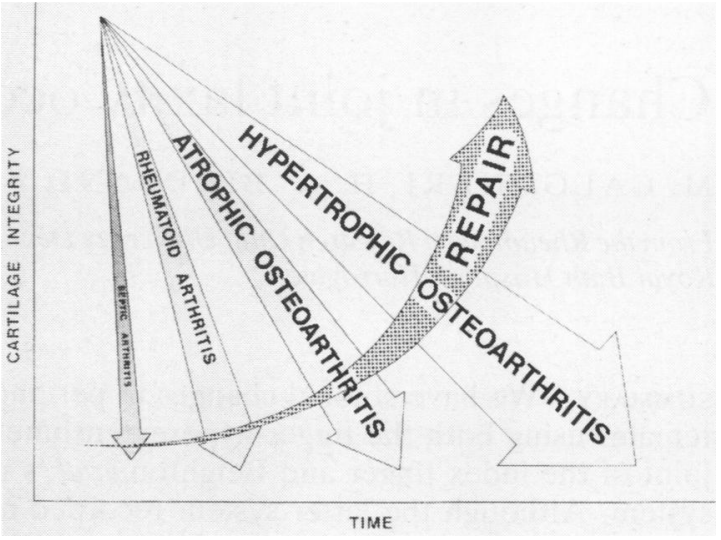

Fig. 12 Diagrammatic representation of the balance between cartilage destruction and repair in different types of arthritis. The more rapid the cartilage destruction the poorer is the bone response; with slow destruction and good bone response the end picture of hypertrophic $O A$ emerges.

time-related process involving the interplay of load, inflammatory disease, and cartilage and bone repair.

We gratefully acknowledge the assistance of DrS. D. Reinach of the Institute of Biostatistics (MRC), Johannesburg.

\section{References}

${ }^{1}$ Kellgren $\mathrm{J}$ H. Osteoarthrosis in patients and populations. Br Med J 1961; 2: 1-6.

${ }^{2}$ Hoagland F T, Yau A C M C, Wong W L. Osteoarthritis of the hip and other joints in Southern Chinese in Hong Kong.J Bone Joint Surg 1973; 55A: 545-57.

${ }^{3}$ Solomon L, Beighton P, Lawrence J S. Rheumatic disorders in the South African Negro. Part II. Osteoarthrosis. S Afr Med J 1975; 49: $1737-40$.

${ }^{4}$ Kellgren $\mathrm{J} \mathrm{H}$, Jeffrey M R, Ball J. The epidemiology of chronic rheumatism. Atlas of Standard Radiographs of Arthritis. Oxford: Blackwell, 1963: 2.

${ }^{5}$ Dequeker J, Burssens A, Creytens G, Bouillon R. Ageing of bone: its relation to osteoporosis and osteoarthrosis in post-menopausal women. Front Horm Res 1975; 3: 116-30.

- Carter J E L. The Heath-Carter somatotype method. San Diego State University, California, 1975: 1.1-H.37.

' Nordin B E C, Young M M, Bulusu L, Horsman A. Osteoporosis re-examined. In: Barzel, U S ed. Osteoporosis. New York: Grune and Stratton, 1970: 47-67.

${ }^{8}$ Solomon L. Bone density in ageing Caucasian and African populations. Lancet 1979; ii: 1326-30.

${ }^{2}$ Foss M V, Byers P D. Bone density, osteoarthrosis of the hip, and fracture of the upper end of the femur. Ann Rheum Dis 1972;31: $259-64$.

${ }^{19}$ Roh Y S, Dequeker J, Mulier J C. Bone mass in osteoarthrosis, measured in vivo by photon absorption.J Bone Joint Surg 1974; 56A: 587-91.

${ }^{11}$ Roh Y S, Dequeker J, Mulier J C. Osteoarthrosis at the hand skeleton in primary osteoarthrosis of the hip and in normal controls. Clin Orthop 1973; 90: 90-4.

12 Yazici H, Saville P D, Salvati E A, Bohne W H O, Wilson P D. Primary osteoarthrosis of the knee or hip. JAMA 1975; 231: 1256-60.

${ }^{13}$ Huskisson E C, Dieppe P A, Tucker A K, Cannell L B. Another look at osteoarthritis. Ann Rheum Dis 1979; 38: 423-8.

${ }^{14}$ Lawrence J S. Rheumatism in Populations. London: Heinemann, 1977. 